\title{
Optical biosensor for catechol determination based on laccase-immobilized anionic polyamide 6 microparticles
}

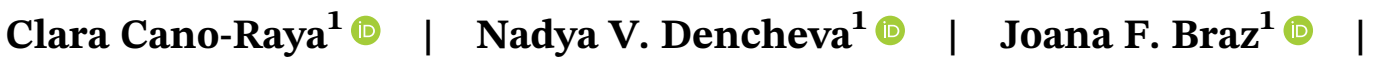 \\ Marc Malfois $^{2}$ () | Zlatan Z. Denchev ${ }^{1}$ (이
}

\begin{abstract}
${ }^{1}$ Department of Polymer Engineering, IPC - Institute for Polymers and Composites, University of Minho, Guimarães, Portugal ${ }^{2}$ ALBA Synchrotron Facility, Cerdanyola del Vallès, Barcelona, Spain
\end{abstract}

\section{Correspondence}

Zlatan Z. Denchev, IPC - Institute for Polymers and Composites, University of Minho, Guimarães 4800, Portugal.

Email: denchev@dep.uminho.pt

\section{Funding information}

European Regional Development Fund, Grant/Award Number: TSSiPRO NORTE01-0145-FEDER-000015; Fundação para a Ciência e a Tecnologia, Grant/Award Numbers: UID/CTM/50025/2019, CTTI51/18-IPC

\begin{abstract}
This work presents the preparation, optimization, and testing of an enzymebased optical biosensor for catechol determination. The sensing area is attached to a glass support and contains: anionic polyamide 6 (PA6) porous microparticles supporting laccase from Trametes Versicolor, embedded in a Pebax $^{\circledR}$ MH1657 polymer binder that contains the optical indicator dye 3-methyl-2-benzothiazolinone hydrazone (MBTH), responsible for the optical transduction. The catechol analyte, after its enzymatic oxidation, forms $o$-benzoquinone that can be detected by oxidative coupling with MBTH giving rise to a colored product. The latter can be quantified measuring the UV/VIS absorbance at $500 \mathrm{~nm}$. The PA6 microparticles performed as useful laccase carriers reaching high immobilization yields of up to $99.8 \%$ and preserving the enzyme catalytic activity. This permitted the preparation of a new biosensor presenting a detection limit of $11 \mu \mathrm{M}$ and responding linearly to up to $118 \mu \mathrm{M}$ of catechol. Biosensor applicability was tested in spiked natural water samples from river and spring. The recovery rates observed were in the range of 97-108\% that proves the good accuracy of the proposed biosensor.
\end{abstract}

\section{KEYWOR D S}

microscopy, optical properties, ring-opening polymerization, sensors and actuators, X-ray

\section{1 | INTRODUCTION}

Catechol is a toxic benzenediol, frequently found in the wastewaters from several industries, for example, petrochemical, pharmaceutical, agrochemical, textile, paper and pulp, among others. ${ }^{[1,2]}$ It has been classified as possibly carcinogenic to humans by the International Agency for Research on Cancer (IARC) ${ }^{[3]}$ and is fatally toxic to fish at concentrations of $5-25 \mathrm{mg} / \mathrm{L}^{[4]}$ Due to its aromatic structure, catechol is very stable and persistent under environmental conditions. ${ }^{[5]}$ Therefore, its removal from wastewater is crucial and its monitoring in industrial effluents is mandatory. ${ }^{[4]}$

Conventional analytical methods for catechol determination include high-performance liquid chromatography, ${ }^{[6]}$ gas chromatography/mass spectrometry, ${ }^{[7]}$ electroanalysis, ${ }^{[8]}$ spectrophotometry, ${ }^{[9]}$ and fluorescence. ${ }^{[10]}$ These techniques provide accurate and precise results but are related with expensive and complex instrumentation. Frequently this results in low frequency analysis, lack of portability and requires skilled personnel. In this context, the development of simple, low-cost, and fast monitoring methods for catechol determination are demanded by the practice.

To evaluate catechol levels, enzyme-based biosensors offer valuable information and provide the required sensitivity, reliability, and selectivity. ${ }^{[11]}$ Different enzymes have been used for biosensors construction, tyrosinase and laccase being among the most used ones. ${ }^{[12-14]}$ In contrast to other enzymes, for example, horseradish 
peroxidase ${ }^{[15]}$ laccase catalyzes the oxidation of catechol by molecular oxygen, not requiring additional oxidation mediators like hydrogen peroxide, ${ }^{[16]}$ which results in simplification of biosensor design.

A critical characteristic of any enzyme-based biosensor is the effective immobilization of the enzyme while maintaining its native catalytic activity. ${ }^{[17]}$ Moreover, in the case of optical laccase sensors, the immobilized enzyme should be able to effectively react with the analyte, whereby the oxidized product should be in direct contact with the optical transducer.

Practically, the biosensing film should provide stability to the enzyme and the transducer agent, permitting at the same time the diffusion of the analyte through it.

Different immobilization methods have been published to ensure the effective enzyme immobilization and the best biosensor performance. ${ }^{[18,19]}$ Covalent binding, based on the chemical activation of groups in the support matrix, has been widely used in biosensors construction. ${ }^{[20-22]}$ It offers increased enzyme resilience against $\mathrm{pH}$ or thermal inactivation but may imply loss in activity of the original enzyme. ${ }^{[23]}$ A particular case of covalent binding is the enzyme cross-linking by polyfunctional reagents. This frequently results in enhanced stability of the enzyme, although large quantities of it are needed. ${ }^{[24,25]}$ In the encapsulation methods, the bioactive agent is confined to the core of micron-sized spheres made from a semipermeable material using physical methods. ${ }^{[26]}$ Another immobilization technique is the entrapment, that is, the confinement of the enzyme in a porous solid matrix. In this case, the enzyme is first suspended in the monomer solution and then the subsequent polymerization arrests the bioactive molecule in the solid polymer matrix. This strategy has been frequently used for biosensors construction based on polyacrylamide. ${ }^{[27,28]}$ Similarly, the doping of inorganic and hybrid organic-inorganic sol-gel polymers with the bioactive molecule has been widely used. ${ }^{[29,30]}$ Finally, physical adsorption is a simple, low cost, and fast immobilization method that attaches the enzyme to a polymer support via noncovalent interactions, for example, electrostatic, H-bonding, or Van der Waals forces. ${ }^{[18]}$ It has not been widely used in biosensors construction because the enzyme immobilization could be mechanically unstable, which means easy desorption and leaching under operating conditions. ${ }^{[31]}$

Once the bioactive molecule is conveniently immobilized, next key factor in biosensors construction is the transduction step. In the literature, many laccase biosensors have been found that are based on electrochemical transduction. ${ }^{[24,32-34]}$ They offer reliable information in a fast and simple way and can be easily miniaturized. The biosensors with optical transduction have emerged as an alternative to electrochemical ones in many applications, since the former do not require a reference electrode and are immune to electromagnetic interference. They can be based on surface plasmon resonance, ${ }^{[35]}$ fluorescence, ${ }^{[36]}$ or absorbance ${ }^{[37]}$ detection. In some cases, authors monitor directly the optical properties of the resultant product from catalytic oxidation of catechol. ${ }^{[14,38]}$ Thus, Sanz et al. use the auto-indicating optical properties of laccase to quantify phenol concentration. ${ }^{[27]}$ However, in most cases, optical biosensors use a chromogenic reagent to optimize the transduction step and improve biosensor response. In this sense, 3-methyl-2-benzothiazolinone hydrazone (MBTH) has been frequently used for the determination of phenolic compounds. ${ }^{[39-41]}$ Since the oxidative coupling of this reagent was described with phenols, aromatic amines, heterocyclic bases, and compounds with active methylene groups, to form highly colored products, MBTH was introduced into analytical chemistry as a sensitive reagent for the detection and photometric determination of carbonyl compounds resultant from enzyme catalyzed oxidation of phenolic compounds. ${ }^{[42]}$

This work presents the first construction and testing of an optical disposable biosensor for catechol determination integrating: (a) previously synthesized porous anionic PA6 microparticles (PA6 MP) in which laccase is immobilized by physical adsorption, embedded in (b) a semipermeable polymer matrix that contains the optical indicator MBTH and permits catechol diffusion, preventing at the same time the enzyme leakage. The sensing scheme is divided into two steps: (a) biological recognition based on the catalytic oxidation of catechol by laccase and (b) optical transduction by formation of a pink-colored adduct between the oxidation product (o-benzoquinone) and MBTH chromophore (Figure 1). To the best of our knowledge, such a biosensor containing anionic PA6 porous microparticles is developed for the first time.

\section{MATERIALS AND METHODS}

\section{1 | Materials}

Catechol (99\%), resorcinol (99\%), and MBTH (3-Methyl2-benzothiazolinone hydrazone hydrochloride hydrate, 97\%) were purchased from Alfa Aesar (UK). Hydroquinone (99.5\%) was supplied by Acros Organics (Belgium). Laccase (E.C. 1.10.3.2; from Trametes versicolor, $\geq 0.5 \mathrm{U} / \mathrm{mg}$ ), ABTS (2,2'-Azino-bis[3-ethylbenzothiazoline-6-sulfonic acid] diammonium salt, 98\%), sodium phosphate monobasic dihydrate $\left(\mathrm{H}_{2} \mathrm{NaO}_{4} \mathrm{P} \cdot 2 \mathrm{H}_{2} \mathrm{O}, 99 \%\right.$, purum p.a.), and sodium phosphate dibasic dihydrate $\left(\mathrm{HNa}_{2} \mathrm{O}_{4} \mathrm{P} \cdot 2 \mathrm{H}_{2} \mathrm{O}, 98 \%\right.$, purum p.a.) were purchased from Sigma-Aldrich. Pebax MH 1657 was kindly donated by Arkema (Serquigny, France). Ethanol absolute p.a. from Panreac (Spain) was used to prepare benzenediol stock solutions and deionized water was used to prepare phosphate buffers and enzyme solutions. As film 
supports, glass microscope slides $75 \times 25 \mathrm{~mm}^{2}$ and $1 \mathrm{~mm}$ thick were provided by Normax (Portugal).

Reagents for the synthesis of PA6 microparticles: $\varepsilon$-caprolactam (ECL) monomer with reduced moisture content for activated anionic polymerization (AP-Nylon ${ }^{\circledR}$ caprolactam) was delivered from Brüggemann Chemical, Germany. Before use, it was kept under vacuum for $1 \mathrm{hr}$ at $23^{\circ} \mathrm{C}$. As polymerization activator, Brüggolen $\mathrm{C} 20^{\circledR}$ (C20) from Brüggemann Chemical, Germany was used. The initiator sodium dicaprolactamato-bis-(2-methoxyethoxo)-aluminate (Dilactamate $\left.{ }^{\circledR}, \mathrm{DL}\right)$ was purchased from Katchem, Czech Republic, and used without further treatment. The chemical structures of ECL, C20, and DL are presented in Figure 2. Toluene, xylene, methanol, and other solvents for synthesis were purchased from Sigma-Aldrich and used as received.

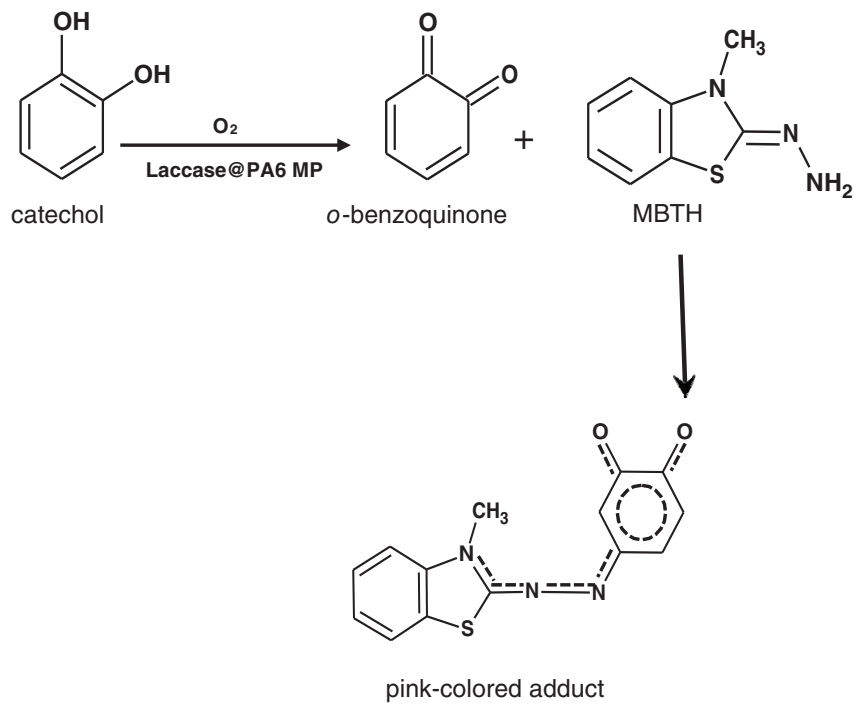

FI G U RE 1 Sensing scheme of the laccase@PA6 MP biosensor

\section{2 | Synthesis of PA6 microparticles}

The PA6 microparticles (PA6 MP) were synthesized by activated anionic ring-opening polymerization (AAROP) as previously described by Dencheva et al. $^{[43]}$ In a typical synthesis, $0.5 \mathrm{~mol}$ of ECL was added to $100 \mathrm{ml}$ of a mixed hydrocarbon solvent (toluene/xylene 1:1 by volume) while stirring, under nitrogen atmosphere, refluxing the reaction mixture for $10-15 \mathrm{~min}$. Subsequently, $3.0 \mathrm{~mol} \%$ of DL and $1.5 \mathrm{~mol} \%$ of $\mathrm{C} 20$ were added at once. The reaction time was always $1 \mathrm{hr}$ (from the point of catalytic system addition) and the temperature was maintained in the $125-135^{\circ} \mathrm{C}$ range at a constant stirring of about $800 \mathrm{rpm}$. The PA6 microparticles formed as a fine powder were separated from the reaction mixture by hot vacuum filtration, washed several times with methanol and dried for $30 \mathrm{~min}$ in a vacuum oven at $60^{\circ} \mathrm{C}$ (see AAROP reaction scheme in Figure 2).

\subsection{Instrumentation and measurements}

Absorbance measurements were carried out using a UV/VIS-2401PC double-beam spectrophotometer (Shimadzu Corp., Japan) with a thin film holder that enables the interrogation of the sensing area. The size distribution of the PA6 microparticles was determined based on bright field optical measurements performed in an Olympus $\mathrm{BH}-2$ microscope (Olympus Corp., Japan) equipped with a Leica DFC200 digital camera (Leica Microsystems, Germany) using the Leica Application Suite 4.4 software for image processing. The scanning electron microscope (SEM) studies were made in a NanoSEM-200 apparatus of FEI Nova (USA) using mixed secondary electron/back-scattered electron in-lens detection. The samples were observed directly after sputter coating with $\mathrm{Au} / \mathrm{Pd}$ alloy in a $208 \mathrm{HR}$ equipment of Cressington Scientific

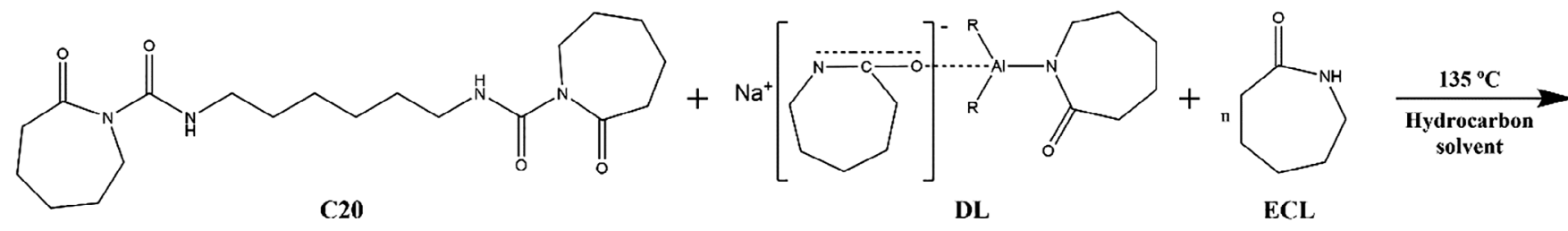

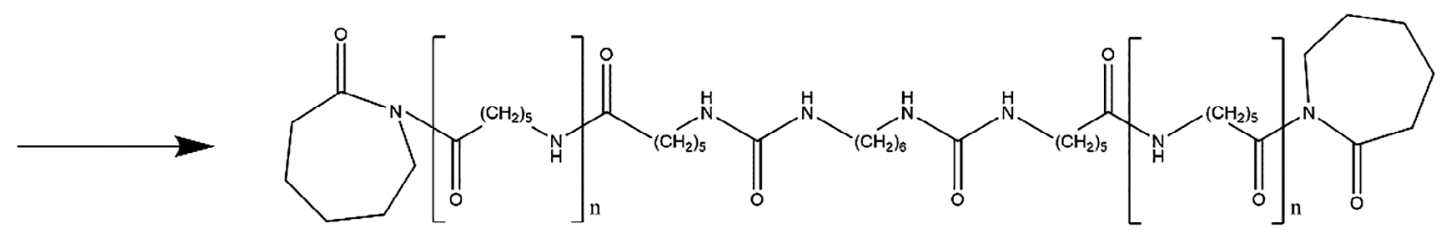

Polyamide 6

FI G U RE 2 Schematic representation of activated anionic ring-opening polymerization of $\varepsilon$-caprolactam to PA6 performed in solution. $\mathrm{R}=\mathrm{OCH}_{2} \mathrm{CH}_{2} \mathrm{OCH}_{3} ; \mathrm{DL}=$ anionic initiator; $\mathrm{C} 20=$ activator 
Instruments (UK) with high-resolution thickness control. The molded samples were observed after cryofracture.

Synchrotron wide- and small-angle X-ray scattering measurements were performed in the NCD-SWEET beamline of the ALBA synchrotron facility in Barcelona, Spain. ${ }^{[44]}$ Two-dimensional detectors were used, namely LH255-HS (Rayonix) and Pilatus 1M (Dectris, Switzerland) for registering the WAXS and SAXS patterns, respectively. The sample-to-detector distance was set to $111.7 \mathrm{~mm}$ for WAXS and $2,700 \mathrm{~mm}$ for SAXS measurements, the wavelength $\lambda$ of the incident beam being $0.1 \mathrm{~nm}$ and the beam size- $0.35 \times 0.38 \mathrm{~mm}(\mathrm{~h} \times \mathrm{v})$. The two-dimensional data were reduced to one-dimensional data using pyFAI software. ${ }^{[45]}$ For processing of the WAXS and SAXS patterns the commercial packages Peakfit 4.12 by SeaSolve Software and SasView Version 4.2, Zenodo, 10.5281/zenodo.1412041 were implemented.

\section{4 | Procedure for laccase immobilization in PA6 microparticles}

Laccase enzyme was immobilized using physical adsorption method. The aqueous laccase solution $(2 \mathrm{mg} / \mathrm{ml})$ was added to $450 \mathrm{mg}$ of PA6 MP in a centrifuge tube. After $24 \mathrm{hr}$ rocker shaking at $37^{\circ} \mathrm{C}$, the supernatant was removed by centrifugation at $9,000 \mathrm{rpm}$ for $15 \mathrm{~min}$. Thereafter, the residual enzymatic activity in the supernatant was determined by ABTS oxidation test. The resultant immobilized material (Laccase@PA6 MP) was stored at $5^{\circ} \mathrm{C}$ until biosensor construction.

\section{5 | Determination of enzyme activity}

Laccase activity was measured using ABTS oxidation test. ${ }^{[24]}$ The UV/VIS absorbance was measured at $25^{\circ} \mathrm{C}$ and $414 \mathrm{~nm}$ using a quartz cuvette of $10 \mathrm{~mm}$ light path. The reaction was performed by adding $1 \mathrm{ml}$ of enzyme solution, $1 \mathrm{ml}$ of sodium phosphate buffer (SPB: $12.5 \mathrm{mM}$; pH 5) and $100 \mu \mathrm{l}$ of $5 \mathrm{mM}$ ABTS solution. One activity unit corresponds to the quantity of enzyme which oxidizes $1 \mu \mathrm{mol}$ of ABTS per minute monitored at $414 \mathrm{~nm}$. The efficiency of immobilization was expressed as immobilization yield (IY) and calculated according to the following equation ${ }^{[46]}$ :

$$
\mathrm{IY}[\%]=\frac{\text { initial activity-SN activity }}{\text { initial activity }} \times 100
$$

where "initial activity" means the laccase activity in the initial aqueous laccase solution before immobilization and "SN activity" represents the activity of remaining laccase in the supernatant after immobilization.

\subsection{Biosensor construction}

Biosensor films were produced on glass slides by solventcasting method (Figure 3). First, the Pebax ${ }^{\circledR}$ MH1657 solution ( $5 \mathrm{wt} \%$ ) was prepared by refluxing Pebax granules in EtOH: $\mathrm{H}_{2} \mathrm{O}(70: 30 \mathrm{vol} / \mathrm{vol})$ mixture for $1 \mathrm{hr}$ at $80^{\circ} \mathrm{C}$. The resultant solution was cooled down to room temperature before mixing with the laccase@PA6 MP. Then, mixtures containing $150 \mathrm{mg}$ of laccase@PA6 MP and $150 \mu \mathrm{l}$ of the previously prepared Pebax solution including the optical indicator MBTH $(1.5 \mathrm{mg} / \mathrm{ml})$, were used to prepare the catechol-sensing films.

The single-use biosensors were cast by placing approximately $11 \mathrm{mg}$ of the previous mixture on the interrogation area of the glass supports. Then, they were left to dry in $\mathrm{EtOH} / \mathrm{H}_{2} \mathrm{O}$ atmosphere at $5^{\circ} \mathrm{C}$ for $24 \mathrm{hr}$ to enable slow evaporation of the solvent. The as-prepared biosensing films were well-adhered to the glass support with a $10 \mathrm{~mm}$ diameter of the circular sensing area.

\section{7 | Catechol assay and water samples analysis}

Biosensors were placed in an aliquot of aqueous standard solution $(15 \mathrm{ml})$ containing between 5 and $500 \mu \mathrm{M}$ of catechol in SPB (25 mM; pH 6) for 30 min without agitation. In the case of natural water samples, $50 \mathrm{ml}$ solutions were prepared by adding $30 \mu \mathrm{l}$ of $50 \mathrm{mM}$ catechol solution $(30 \mu \mathrm{M}$ final concentration of catechol) and $2.5 \mathrm{ml}$ of a concentrated SPB (500 mM; pH 6) in order to avoid excessive dilution of original water samples. The as-prepared water samples were divided into three aliquots of $15 \mathrm{ml}$ each in order to test them in triplicate with three different disposable sensors. Next, the sensing films were taken out from the solution to be characterized, wiped to remove any solution droplets and their absorbance was measured at $500 \mathrm{~nm}$ and compared against a reference sensor prepared in the same way and equilibrated in SPB ( $25 \mathrm{mM}$; pH 6) without catechol. The absorbance measurements were carried out by using a holder for the thin films and two black masks with central holes of $6 \mathrm{~mm}$ in diameter ( $<10 \mathrm{~mm}$ sensing area) to delimit the surface of the UV/VIS light beam and avoid the possible refraction phenomena produced in the edges of the biosensor and reference films. The analytical parameter used for catechol quantification was the increase in absorbance at $500 \mathrm{~nm}\left(\triangle A=A-A_{0}\right)$, wherein $A$ is the biosensor absorbance after reaction with catechol and $A_{0}$ is the initial absorbance after biosensor equilibration in SPB ( $25 \mathrm{mM}$; pH 6) for $5 \mathrm{~min}$. All measurements were carried out at room temperature. 


\section{3 | RESULTS AND DISCUSSION}

\section{1 | Structure and morphology of anionic PA6 microparticles}

The morphology of the PA6 microparticles before and after laccase immobilization was revealed by SEM as presented in Figure 4.

As seen from Figure 4a, the neat anionic PA6 MP synthesized by AAROP display a particulate morphology with a Gaussian size distribution centered between 40 and $55 \mu \mathrm{m}$ (the three central bars of the histogram), the shape of the particles being close to spherical. Higher magnifications with the same sample display the extremely porous, scaffold-like topography of the PA6
MP with a system of integrated 3D pores and channels, the average visible pore diameters varying between 150 and $450 \mathrm{~nm}$. After laccase immobilization (Figure 4b) neither the shape nor the size distribution of the particles changes significantly. The topography of the laccase@PA6 MP samples, however, is notably different. The surface pores and channels with small and medium sizes become covered and concealed by the adsorbed enzyme, leaving relatively unblocked only the largest visible cavities of $350-400 \mathrm{~nm}$. Such an observation is a direct proof of the physical deposition of the enzyme upon the MP surface.

It should be noted that the above microscopy studies cannot assess whether or not the invisible cavities of the neat microparticles were filled with enzyme, as well as

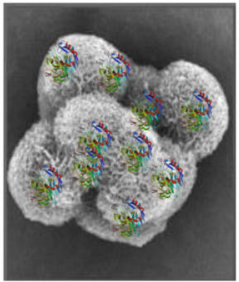

Laccase@PA6 MP

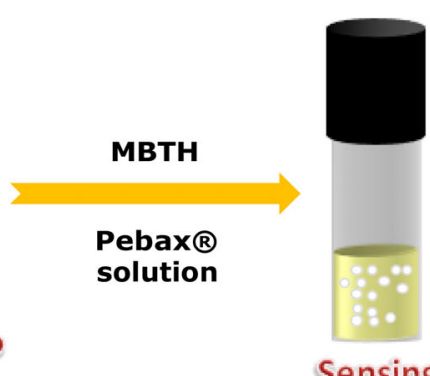

Sensing solution
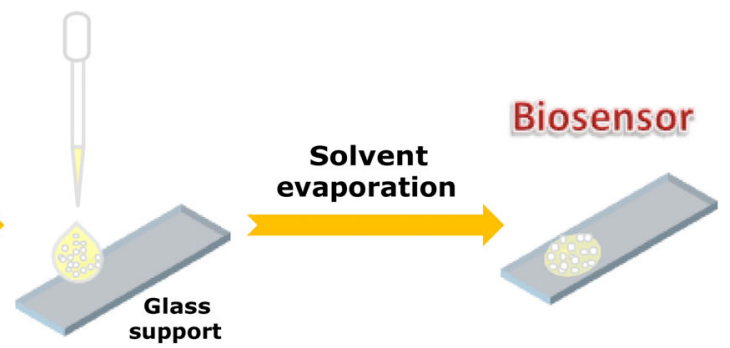

support

\section{construction}

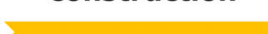

F I G U RE 3 Schematic representation of biosensor construction [Color figure can be viewed at wileyonlinelibrary.com]

(a)
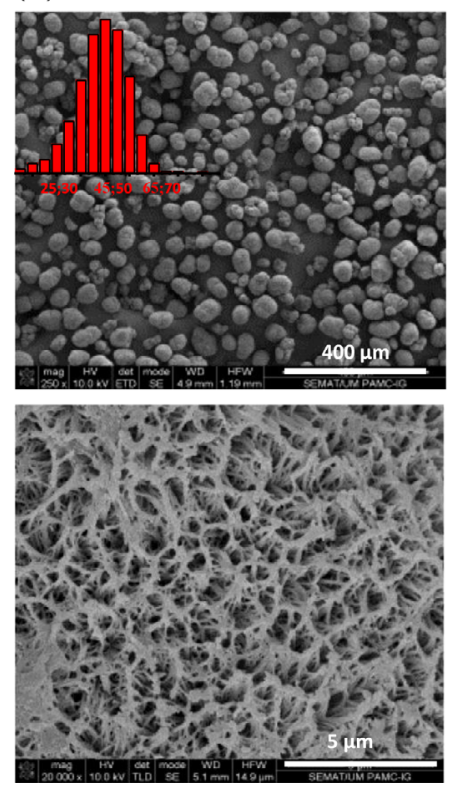

(b)
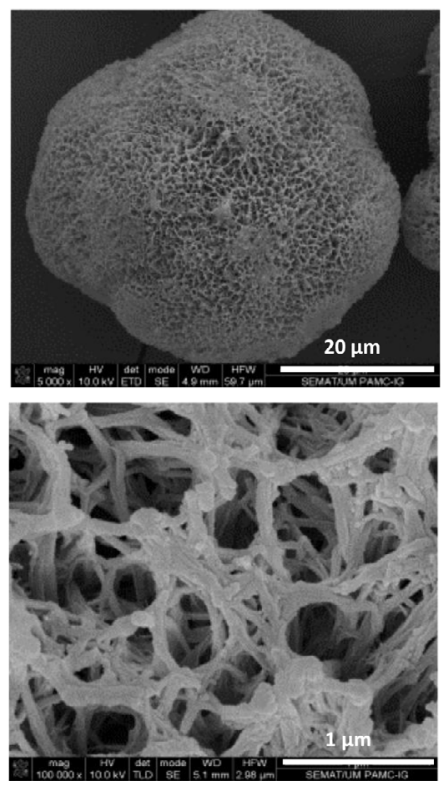
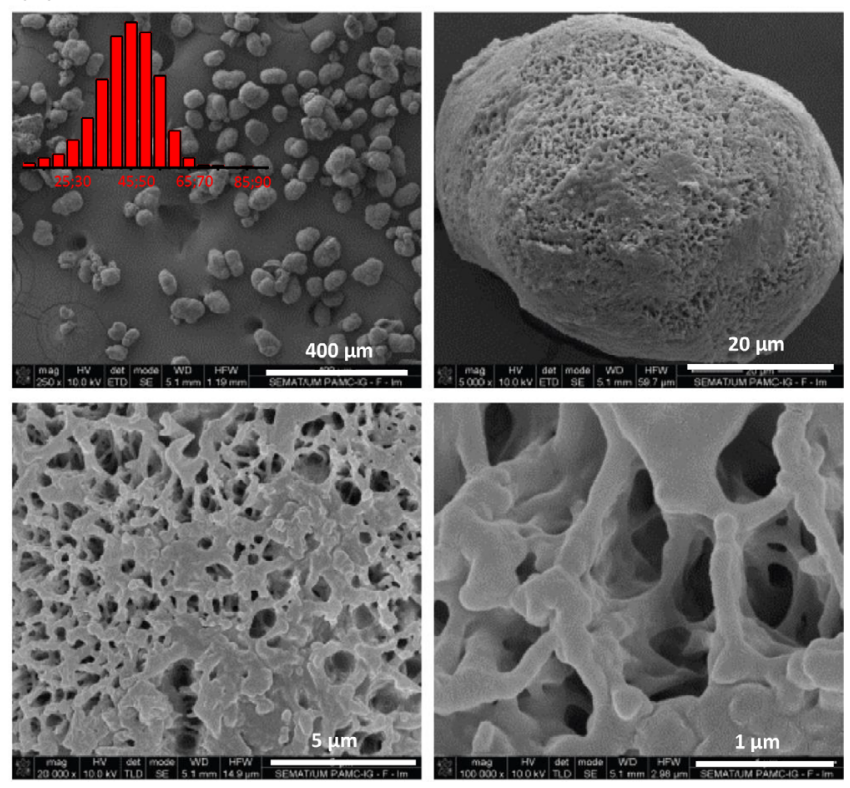

F I G U RE 4 Scanning electron microscope micrographs of PA6 MP (a) and laccase@PA6 MP (b) at various magnifications. The inset histograms represent the size distributions of the particles and the predominating microparticles fractions in microns obtained by brightfiled optical microscopy [Color figure can be viewed at wileyonlinelibrary.com] 
the possibility that the laccase adsorption could somehow modify the proper enzyme, or the crystalline structure of the PA6 support. These factors are closely related to the immobilization effectiveness. Therefore, in an attempt to evaluate them, synchrotron WAXS and SAXS were employed. Thus, Figure 5 presents the initial WAXS linear patterns of neat PA6 MP (curve 1), laccase@PA6 MP (curve 2), and free laccase (curve 3), after subtraction of the empty chamber scattering. It should be noted that WAXS probes the periodicity in the crystalline structure in the length-scale of various angstroms returning information about the unit cell.

The neat PA6 anionic microparticles display the crystalline structure typical of PA6, with two reflections at $q=14.3$ and $16.89 \mathrm{~nm}^{-1}$. As pointed out in previous Xray studies, ${ }^{[47,48]}$ these WAXS peaks correspond to the [200] and [002/202] crystalline planes of the $\alpha$-PA6 monoclinic unit cell. The free laccase produces a wide diffuse scattering peak (halo) typical of amorphous materials and centered at $q_{a}=13.0 \mathrm{~nm}^{-1}$. The pattern of laccase@PA6 MP represents a superposition of the previous two curves, whereby the two $\alpha$-PA6 reflections apparently maintain their form and angular position and, in addition, an amorphous halo centered at $q_{a}=19.7 \mathrm{~nm}^{-1}$ appears. Evidently, the latter should be attributed to the adsorbed laccase that, at the length scale probed by WAXS, is to be considered disordered. The shift of the enzyme amorphous halo is significant $\left(\Delta q_{a}=6.7 \mathrm{~nm}^{-1}\right)$ and can be explained as follows. Since the amorphous halo in WAXS is related to the intermolecular interactions, ${ }^{[49]}$ its position must be dependent on the degree of packing of the molecules (i.e., the density) of the respective amorphous phase. According to

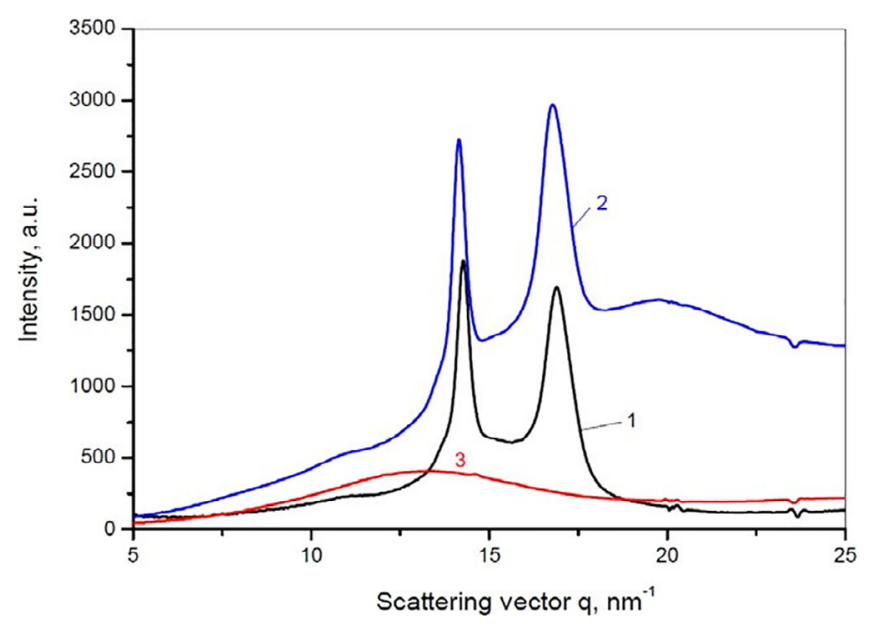

F I G U R E 5 Initial WAXS linear patterns of: 1, PA6 MP; 2, laccase@PA6 MP; 3, free laccase. Linear patterns after empty chamber scattering subtraction [Color figure can be viewed at wileyonlinelibrary.com]
Alexander, ${ }^{[50]}$ the dependence of the amorphous halo angular position $q_{a}$ on the intermolecular distance $r_{a}$ could be given as:

$$
r_{a} \frac{\tilde{\lambda}}{2 q_{a}}
$$

Equation (2) is the reciprocal dependence typical of all diffraction phenomena, that is, the larger the scattering vector $q_{a}$ value, the smaller the intermolecular distance and consequently the higher the density. This means that the adsorbed enzyme in the laccase@PA6 sample has a denser packing as compared to the free one, which should be attributed to intensive interaction between the laccase and PA6 macromolecules via multiple $\mathrm{H}$-bonds. An additional result of the laccase immobilization is the abrupt increase of the background at higher $q$ values in the laccase@PA6 MP sample that cannot be compensated by subtraction of the empty chamber radiation.

Further information about the crystalline structure of the samples can be extracted after deconvolution of the WAXS patterns in Figure 6 by peak fitting. This procedure and the subsequent quantification of the $\alpha$ - and $\gamma$-PA6 crystalline phases are discussed in detail in earlier publications. ${ }^{[51]}$ The result of this procedure for the PA6 MP and laccase@PA6 MP is demonstrated in Figure 6. In both samples, excellent fits with $r^{2}>.99$ were obtained. The respective numeric data are presented in Table 1.

As seen from Figure 6a,b, the deconvolution reveals the amorphous and crystalline fractions in the PA6 MP before and after laccase immobilization, showing at the same time the polymorph content and the $\alpha / \gamma$ relation. Thus, in the initial PA6 MP sample the $X_{c}$ (coinciding in this case with the sum of $\alpha$-PA6 $+\gamma$-PA6) is $44.3 \%$, whereby $\alpha / \gamma=2.89$. These parameters are typical for PA6 MP obtained by AAROP. After laccase immobilization, the enzyme amorphous halo contributes with $17 \%$ to the total sample scattering. The $\alpha / \gamma$ ratio for this sample is slightly higher than in the neat PA6 MP due to the $4 \%$ lesser $\gamma$-PA6 concentration, but this difference is within the margin of the experimental error of the deconvolution.

Using synchrotron SAXS allows further clarification of the structure of the microparticles before and after enzyme immobilization. This method probes density periodicities with dimensions in the 20-250 $\mathrm{\text {range}}$, which includes the sizes of the crystalline lamellae typically found in semicrystalline polymers. Thus, a peak in the SAXS profile of such a polymer with a maximum of $q_{\text {max }}$ (reciprocal space) would give in the real space $\left(q_{\max }{ }^{-1}\right)$ the Bragg's long period $L_{\mathrm{B}}$ of the respective periodicity, whereby 


$$
L_{\mathrm{B}}=l_{c}+l_{a}
$$

$l_{c}$ and $l_{a}$ being the average thicknesses of the crystalline and amorphous layer of the periodicity.

Figure 7 presents the Lorentz-corrected SAXS linear profiles of PA6 MP (a), the laccase immobilized sample (b), and the free laccase (c). It can be seen that the PA6 MP displays a very subtle Bragg peak with poorly resolved $q_{\max }$ with $L_{\mathrm{B}}$ value between 90 and $95 \AA$, which

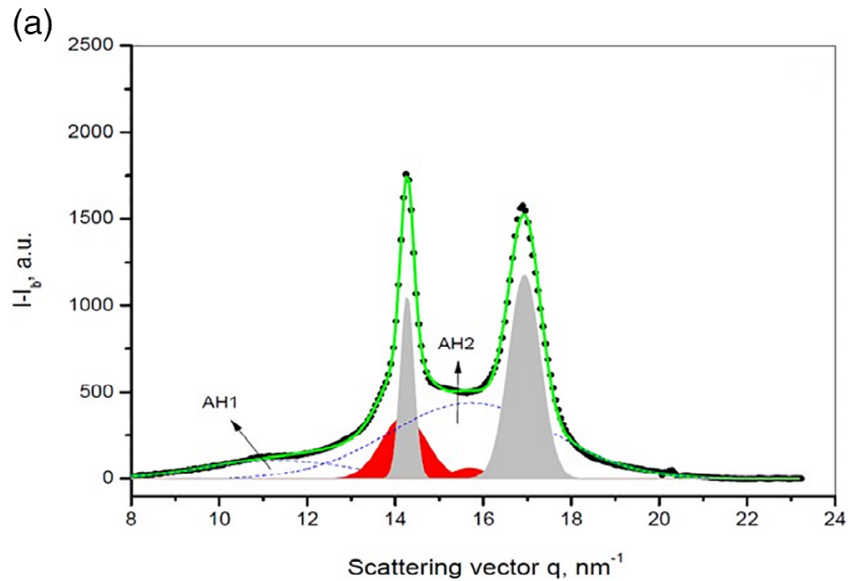

(b)

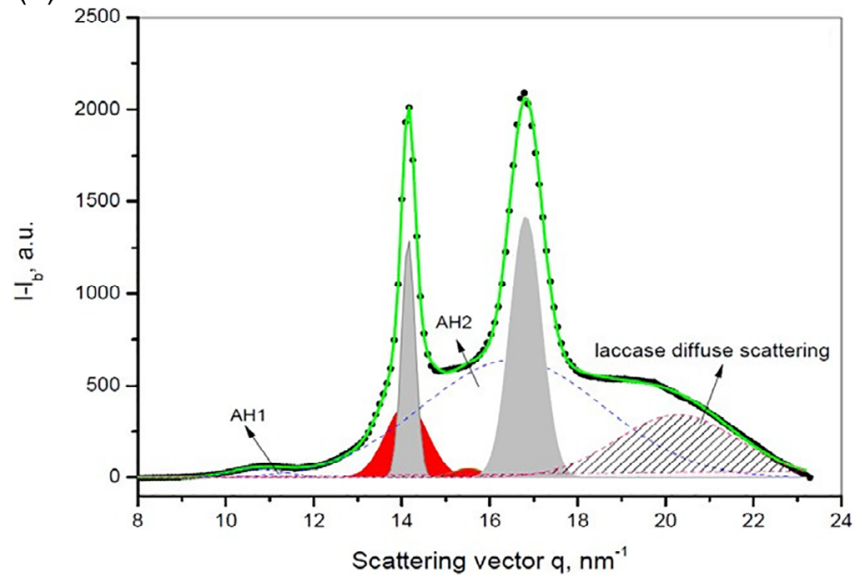

F I G U RE 6 WAXS patterns deconvoluted by peak fitting: (a) neat PA6 MP; (b) Laccase@PA6 MP. Gray: $\alpha$-PA6 crystalline peaks; Red: $\gamma$-PA6 crystalline peaks; $\mathrm{AH} 1$ and $\mathrm{AH} 2$-diffuse peaks of the PA6 amorphous fraction. Empty chamber scattering and background corrections applied (For the interpretation of the indicated colors in this figure, the reader is directed to the web version of this article) [Color figure can be viewed at wileyonlinelibrary.com] is typical of isotropic annealed PA6. ${ }^{[51]}$ Moreover, the PA6 MP display one weak peak at $q=3.7 \mathrm{~nm}^{-1}$ $\left(L_{\mathrm{B}}=17 \AA\right.$ ) that should be related to the MP porosity. The free laccase does not show any periodicity in the SAXS q-range i.e., agrees with the WAXS results. Quite interestingly, the laccase@PA6 MP (curve 2 in Figure 7) displays a very well resolved SAXS peak with an $L_{\mathrm{B}}=87 \AA$, whereby the porosity peak is not present anymore. Linear profile 2 indicates also a much better phase contrast between the densities of the amorphous and crystalline regions in the immobilized sample, as compared to the neat PA6 MP support. Based on the SAXS data, it can be supposed that the low phase contrast in the neat support MP is due to the large fraction of empty pores and channels that decrease significantly the volume of the irradiated material. After laccase immobilization, most of the cavities get filled with enzyme whose density should be comparable to that the amorphous PA6. This creates a clearer density gradient between the amorphous and crystalline parts of the lamellar periodicity resulting in a better resolved SAXS peak.

\section{2 | Immobilization of laccase upon PA6 MP}

Construction of biosensors requires stable immobilization of the bioactive compound upon the support to exclude its easy desorption and leaching under operating conditions. Therefore, the covalent binding between the enzyme and support seems to be the more advantageous immobilization technique for biosensors. The covalent binding, however, may inactivate the enzyme. In order to avoid it, the use of suitable spacers is required to optimize the distance between the enzyme and the polymer support, ${ }^{[20]}$ thus making the immobilization quite complex. It has been described that with the use of a spacer ${ }^{[46,52]}$ the IY could be enhanced to approximately $50 \%$. On the other hand, Patel et al. presented porosity of the support as a key factor for effective enzyme loading, ${ }^{[53]}$ however, covalent binding with glutaraldehyde activation of porous $\mathrm{Fe}_{2} \mathrm{O}_{3}$ was necessary so as to reach a IY of $90.6 \%$.

Based on the above structural studies, it can be assumed that the immobilization of laccase upon anionic
T A B L E 1 Polymorph content and total crystallinity index $X_{c}$ extracted from the WAXS pattern analysis

\begin{tabular}{llllll} 
Sample & $\boldsymbol{\alpha} \%$ & $\boldsymbol{\gamma} \boldsymbol{\%}$ & $\boldsymbol{\alpha}+\boldsymbol{\gamma} \boldsymbol{\%}$ & $\boldsymbol{X}_{\boldsymbol{c}}, \boldsymbol{\%}$ & $\frac{\alpha}{\gamma}$ \\
\hline Neat PA6 MP & 32.7 & 11.6 & 44.3 & 44.3 & 2.82 \\
\hline Laccase@PA6 MP & 25.8 & 7.6 & 33.4 & $40.2^{\mathrm{a}}$ & 3.39 \\
\hline
\end{tabular}

${ }^{\mathrm{a}}$ Value obtained without considering the laccase diffuse scattering whose contribution is $17 \%$ of the sample volume. 
PA6 MP by physical adsorption results in filling of most of the cavities of the microparticles by the enzyme and in some deposition of it on the particles surface. The enzyme and the support interact by interphase H-bond formation, whereby the packing of the enzyme becomes denser. At the same time, the multiple H-bonds across the laccase/PA6 support interface are expected to provide a good attachment of the enzyme. Therefore, the combination of highly porous support and intensive H-bond formation could favor a stable laccase immobilization by physical adsorption upon the PA6 MP.

The results of the ABTS activity test performed with free laccase and with such remaining in the supernatant after immobilization completion with various amounts of PA6 MP is presented in Figure 8.

An IY $=99.8 \%$ was reached with a PA6 MP sample of $500 \mathrm{mg}$ by using the physical adsorption method for enzyme immobilization, without the need of preliminary activation of PA6 microparticles. This justifies the use of PA6 microparticles as enzyme carriers in biosensor construction.

\section{3 | Biosensor composition}

The above morphological, structural, and immobilization studies permitted to construct a novel biosensor for catechol determination based on polymer-immobilized enzyme. Thus, the components that form the biosensing film are: the enzyme-carrier laccase@PA6 MP conjugate that was prepared by us, the chromogenic transductor MBTH, and a semipermeable polymer matrix-the commercial Pebax ${ }^{\circledR}$ MH1657. The role of the latter is to

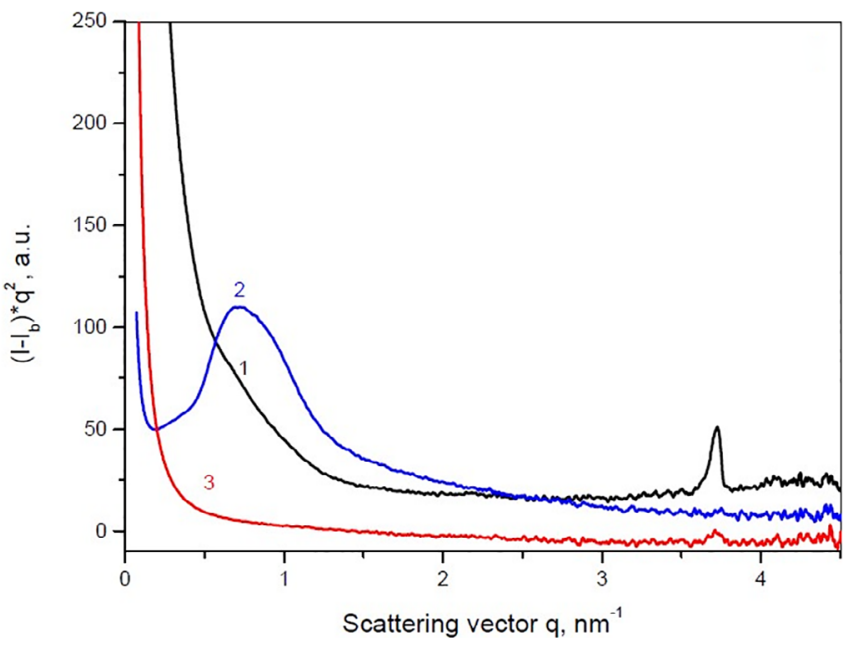

F I G U R E 7 SAXS data and their treatment: Lorentz-corrected patterns (Kratky plots) of PA6 MP (1), laccase@PA6 MP (2), and free laccase (3) [Color figure can be viewed at wileyonlinelibrary.com] enable analyte diffusion while retaining the laccase@PA6 MP conjugate and the MBTH indicator, placing them in the interrogation light path of the spectrophotometer. Thus, after studying the laccase immobilization process (Figure 8), $450 \mathrm{mg}$ of PA6 MP was selected as the optimal amount to reach an IY of up to $99 \%$. Larger quantities of PA6 MP leading to total laccase immobilization (IY of $100 \%$ ) were not implemented, as they could imply the existence of empty particles, which would be detrimental for the biosensor response.

MBTH was chosen as chromogenic reagent because it reacts by oxidative coupling with $o$-benzoquinone resulting from the catalytic oxidation of catechol caused by the laccase. ${ }^{[41,54]}$ MBTH traps the $o$-benzoquinone forming a colored stable adduct (Figure 1) with $\lambda_{\max }$ at $500 \mathrm{~nm}$ and a molar extinction coefficient of $32,500 \mathrm{M}^{-1} \mathrm{~cm}^{-1}$. ${ }^{[5]}$ The color in the visible part of the UV/VIS region should be attributed to the formation of conjugated covalent bond system indicated by dashed lines. Quite importantly, this colored adduct is insoluble in water and readily soluble in organic solvents, ${ }^{[42]}$ which should favor its retention in the polymer film avoiding its leaching to aqueous phase. To optimize the MBTH concentration, several biosensors were constructed by varying the MBTH concentration in the polymer mixture between 0.5 and $3 \mathrm{mg} / \mathrm{ml}$. Figure 9 shows that the biosensor response increases with MBTH concentration up to $1.5 \mathrm{mg} / \mathrm{ml}$.

Concentrations of MBTH larger than $1.5 \mathrm{mg} / \mathrm{ml}$ seem to inhibit laccase activity decreasing, therefore, the biosensor response, although the differences are not quite

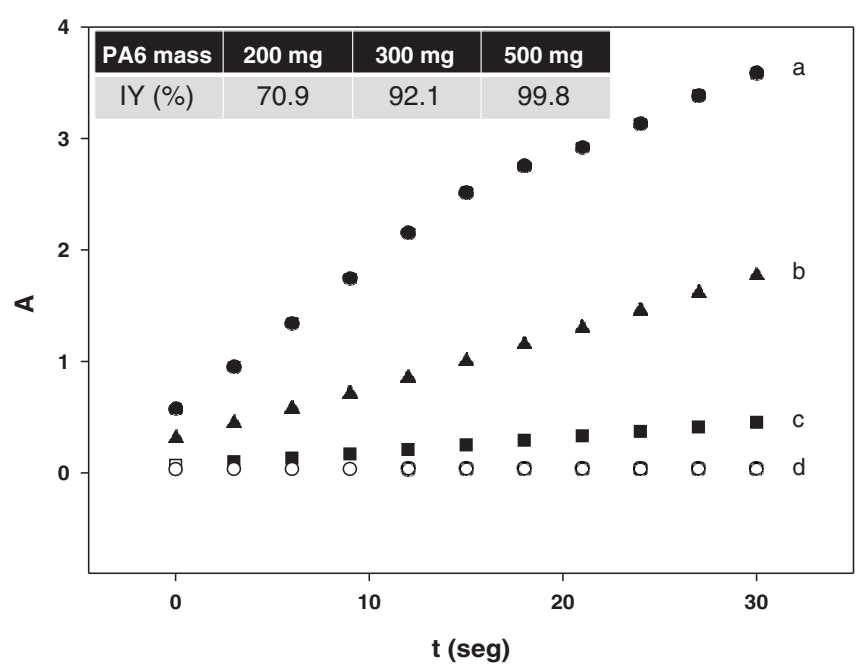

FI G U RE 8 Influence of PA6 MP amount in laccase immobilization process. ABTS activity tests: (a) Fresh laccase ( $2 \mathrm{mg} / \mathrm{ml}$ ); (b) SN of immobilization with $200 \mathrm{mg}$ PA6; (c) SN of immobilization with $300 \mathrm{mg}$ PA6; (d) SN of immobilization with $500 \mathrm{mg}$ PA6. Inset: IY for the different PA6 MP amount used in the immobilization process 
large statistically. Similar finding was previously described by Gul et al., ${ }^{[56]}$ who found enzyme activity inhibition above $6 \mathrm{mM}(1.3 \mathrm{mg} / \mathrm{ml})$ of MBTH.

Among commercially available hydrophilic polymers, Pebax $^{\circledR}$ MH1657 was selected as semipermeable binder for biosensor construction due to its good film-forming ability ${ }^{[57]}$ and its good compatibility with PA6 MP. It is a block copolymeric poly(ether amide) containing polyether (PE) rubbery segments and hard polyamide (PA6) semicrystalline segments ${ }^{[58]}$ (see chemical structure in Figure 10).

Most of its properties that are interesting for biosensor building are associated with the predominating ratio of soft PE blocks versus rigid PA6 segments of 60:40 wt\%. This makes Pebax ${ }^{\circledR}$ MH1657 quite hydrophilic, improving biosensor wetting and catechol diffusion. At the same time, the PA6 blocks provide a moderate hydrophobicity, which could favor MBTH retention in the biosensing film. ${ }^{[37]}$ Moreover, the PA6 blocks in Pebax ${ }^{\circledR}$ MH1657 are expected to favor the miscibility with the laccase@PA6 MP conjugate facilitating its dispersion in the biosensing films. To the best of our knowledge, this is the first time to use Pebax $^{\circledR}$ MH1657 as a semipermeable matrix for biosensor construction. In previous works, this material

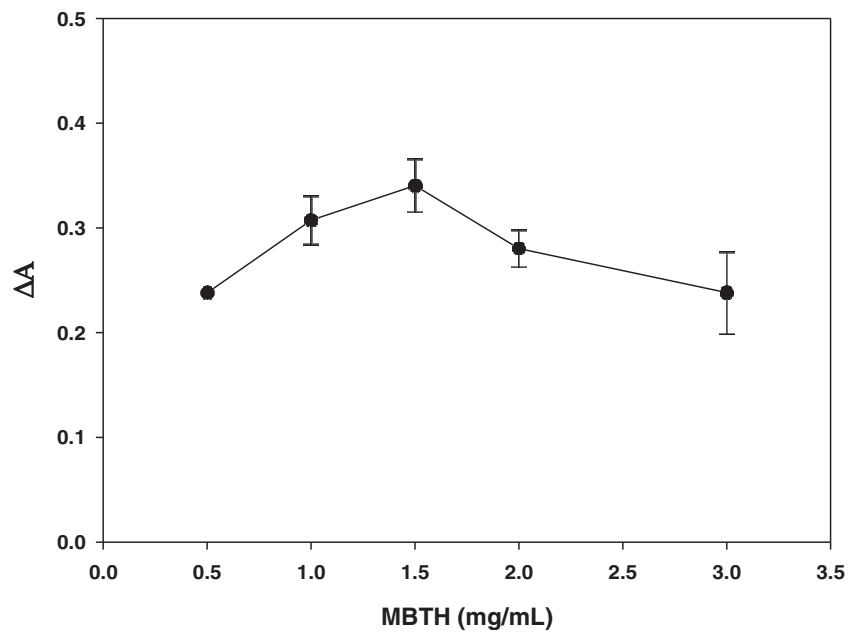

F I G U R E 9 Influence of 3-methyl-2-benzothiazolinone hydrazone (MBTH) concentration on biosensor response at $50 \mu \mathrm{M}$ catechol level and 30 minutes reaction time. Each MBTH concentration was tested in triplicate $(n=3)$

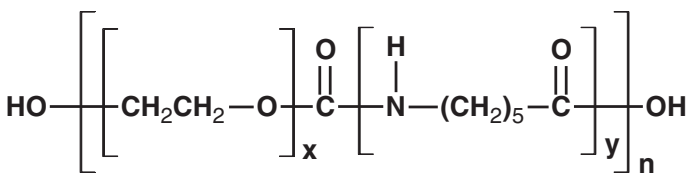

FI G U RE 10 Chemical structure of Pebax ${ }^{\circledR}$ MH1657 $(x / y$ : 60:40 wt $\%)$ has been widely used in gas separation applications ${ }^{[59,60]}$ and in membrane filtration studies. ${ }^{[61,62]}$

The suitability of Pebax ${ }^{\circledR}$ MH1657 for laccase retention was proved in a preliminary experiment that demonstrated the absence of enzyme activity in an aliquot of distilled water that was placed in contact with a biosensor film for $1 \mathrm{hr}$ (Figure 11).

This result can be explained by the specific behavior of the poly(ether amide) copolymer in various liquid media. In hydrophilic media, it swells and behaves as a gel permitting the passage of solutes with molecular weights up to $4,500 \mathrm{~g} / \mathrm{mol},{ }^{[62]}$ but impeding the diffusion of larger biomolecules. This semipermeability is of key importance for the biosensor proper functioning allowing the low-molecular weight catechol to enter, without leaching of immobilized laccase.

\section{4 | Operating conditions for biosensor implementation}

To optimize the parameters related to the operating conditions, the influence of $\mathrm{pH}$ and the contact time between the disposable biosensor and the problem solution were studied. pH directly affects the enzyme catalytic activity and its effect in biosensor response was measured from $\mathrm{pH} 4.5$ to 8.5. Biosensor response increases with $\mathrm{pH}$ value up to 6.5 , decreasing significantly at more basic conditions (Figure 12). Then, $\mathrm{pH} 6$ was selected for further experiments and SPB ( $25 \mathrm{mM}$; $\mathrm{pH}$ 6) was used to prepare the standard solutions. A concentration of $25 \mathrm{mM}$ for SPB was adequate to maintain buffering capacity at $\mathrm{pH} 6$ in natural water samples and concentrated catechol standard solutions. The selected $\mathrm{pH} 6$ value is in agreement

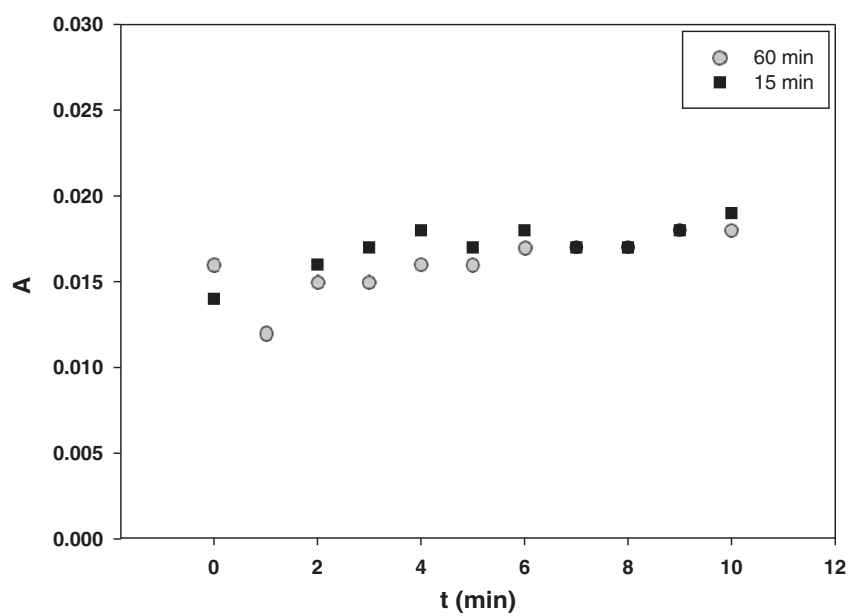

FI G U RE 11 ABTS activity tests in the distilled water placed in contact with a biosensor film. Measurements were done at two contact times: 15 and $60 \mathrm{~min}$ 
with previously published works based on laccaseimmobilized biosensors. ${ }^{[32,41]}$

In order to increase the biosensor sensitivity toward catechol, a contact time of $30 \mathrm{~min}$ was chosen. At this equilibration time, biosensor response reaches a plateau corresponding to $89.5 \%$ of the maximum response registered at $500 \mathrm{~nm}$ for a concentration level of $100 \mu \mathrm{M}$ of catechol (Figure 13).

The reason for this relatively long response time could be twofold, related to the diffusion of the analyte through the sensing film, and the convective mass transport of catechol from the bulk of the aqueous solution to the sensing film. It should be noted that long response times between 25 and 45 min are frequently indicated when immobilized enzymes are used for optical biosensors construction. ${ }^{[17,63]}$

\subsection{Analytical parameters}

The biosensor response was characterized using two series of standards and $30 \mathrm{~min}$ reaction time. The first series of standards is in the maximum slope area (six standards, three replicates each), with catechol concentrations between $5 \cdot 10^{-6}$ and $9 \cdot 10^{-5} \mathrm{M}$, and the second series is in the minimum slope area (three standards, three replicates each), with catechol concentrations between $2 \cdot 10^{-4}$ and $5 \cdot 10^{-4} \mathrm{M}$.

The linearity was proved by lack-of-fit test and a linear calibration function was established in the maximum slope area (Figure 14, inset). The limit of detection using standard criteria, ${ }^{[64]}$ was $11 \mu \mathrm{M}$ of catechol $(1.2 \mathrm{mg} / \mathrm{L})$. The upper limit of the measuring range was calculated from the intersection point of the linear calibration function and the linear function in the minimum slope area; giving a resultant value of $118 \mu \mathrm{M}$ (13.0 mg/L; Figure 14).

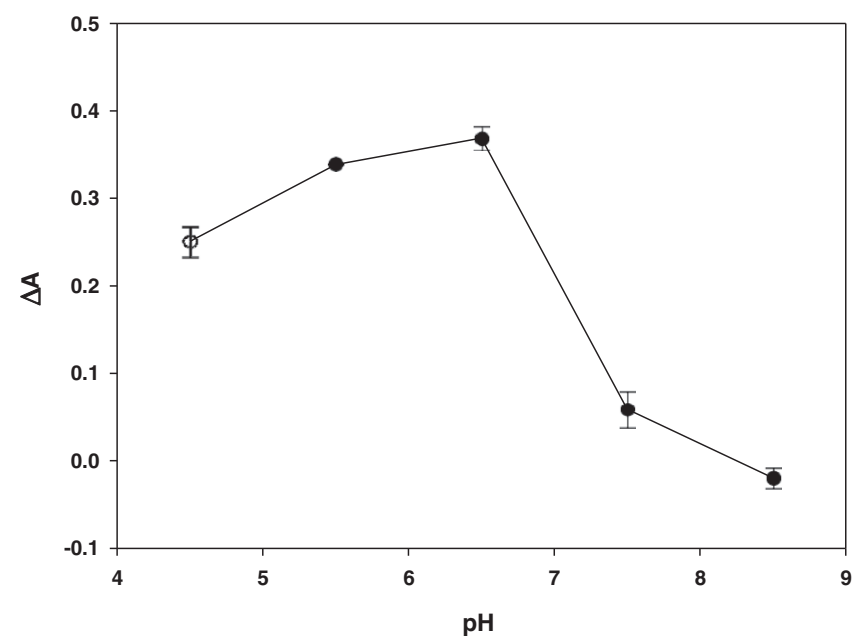

F I G URE 12 Influence of $\mathrm{pH}$ on biosensor response. Reaction conditions: [catechol] $=50 \mu \mathrm{M} ; t=30 \mathrm{~min}$; each $\mathrm{pH}$ value was tested in triplicate $(n=3)$
Discussing the above data, it should be noted that the analytical performance of the laccase-based biosensor presented in this work is noticeably better than other optical biosensors using the MBTH chromophore. For instance, Abdullah et al. presented a multilayer optical biosensor for catechol determination that works in the concentration range of $0.5-8.0 \mathrm{mM}$ with a detection limit of $0.33 \mathrm{mM} \cdot{ }^{[41]}$ In a previous work, the same authors presented a lower detection limit of $0.23 \mathrm{mg} / \mathrm{L}$ for catechol when using tyrosinase instead of laccase. ${ }^{[37]}$ However, the sensitivity of the proposed method was very low. In addition, a paper-based biosensor with laccase and MBTH indicator co-immobilized in a Whatman paper has been presented finding a detection limit of $64 \mu \mathrm{M}$ for cathecol. ${ }^{[54]}$ Again, a decrease in the detection

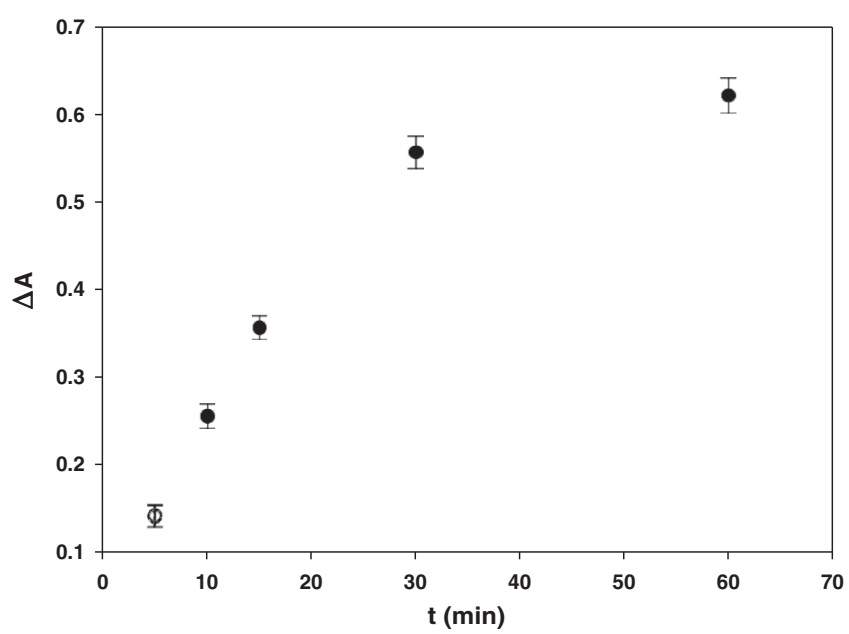

FI G U RE 13 Influence of reaction time on biosensor response. Reaction conditions: [catechol] $=100 \mu \mathrm{M}$; three replicates $(n=3)$

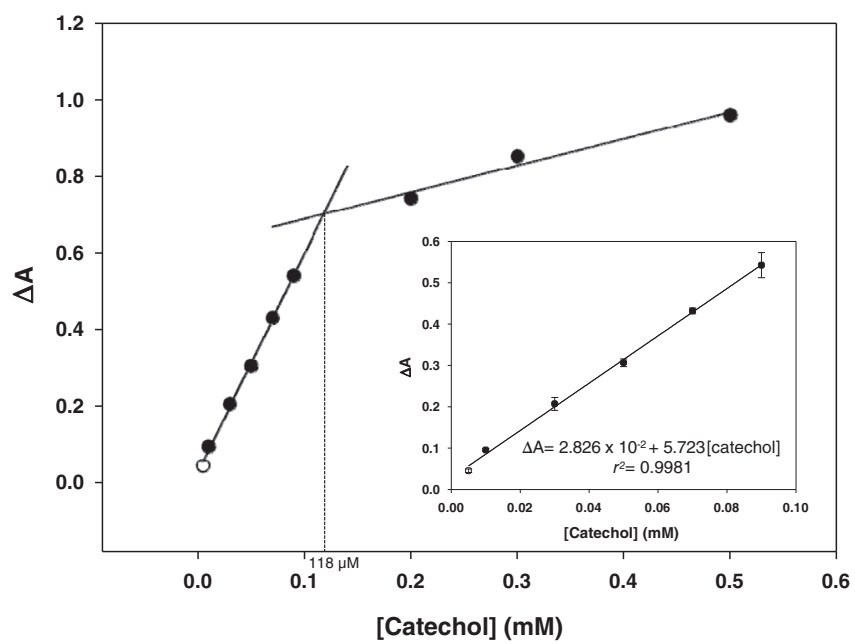

F I G U RE 14 Biosensor calibration plot for catechol determination. Inset: Linear function in the maximum slope area 
limit to $32 \mu \mathrm{M}$ was observed when tyrosinase is used instead of laccase. ${ }^{[40]}$

The precision, expressed as relative standard deviation of catechol concentration, was established using a set of seven different disposable biosensors. It was calculated at a concentration level of $40 \mu \mathrm{M}$ of catechol, giving a resultant value of $6.7 \%$ (Table 2). Biosensor stability was tested at a catechol concentration in the middle of the measuring range using different films that had been stored at $5^{\circ} \mathrm{C}$. Table 2 compiles the resultant analytical parameters.

\section{6 | Selectivity study}

The influence of two positional isomers of catechol, namely resorcinol ( $m$-benzenediol) and hydroquinone ( $p$ benzenediol), on the biosensor response was studied and compared with that obtained for catechol at the same concentration level. In all cases, solutions with $50 \mu \mathrm{M}$ of the corresponding benzenediol were prepared in SPB $(25 \mathrm{mM}$,

TABLE 2 Analytical figures of merit

\begin{tabular}{ll} 
Parameter & Value, $\boldsymbol{S}$ \\
\hline Intercept & $2.826 \cdot 10^{-2} ; 6.597 \cdot 10^{-3}$ \\
\hline Slope & $5.723 ; 0.126$ \\
$r^{2}$ & .9981 \\
LOD & $11 \mu \mathrm{M}(1.2 \mathrm{mg} / \mathrm{L})$ \\
\hline Linear range & $11-118 \mu \mathrm{M}(1.2-13 \mathrm{mg} / \mathrm{L})$ \\
\hline Precision $(\mathrm{RSD})^{\mathrm{a}}$ & $6.7 \%$ \\
\hline Stability & 1 week \\
\hline
\end{tabular}

Abbreviations: LOD, limit of detection; RSD, relative standard deviation. ${ }^{\mathrm{a}} \mathrm{RSD}$ for $[$ catechol] $=40 \mu \mathrm{M}$ and seven replicates $(n=7)$.

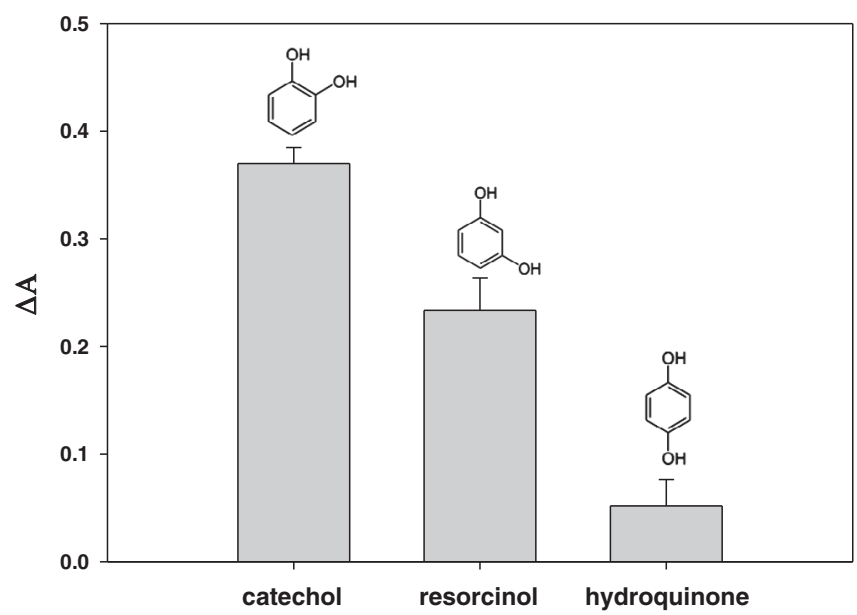

F I G U RE 15 Comparison of biosensor response to catechol and its positional isomers. Reaction conditions:

[benzenediol $]=50 \mu \mathrm{M} ; t=30 \mathrm{~min} ; n=3$
$\mathrm{pH}$ 6) and $\Delta A$ was measured at $500 \mathrm{~nm}$ after $30 \mathrm{~min}$ reaction time. Results show that the biosensor response is higher for catechol than for its positional isomers (Figure 15).

The results in Figure 15 show that the hydroquinone is a weak interferent (below 15\%), however resorcinol interferes strongly. In a previous work, laccase has been described as an effective biological catalyst for the oxidation of $o-, m$, and $p$-benzenediols. ${ }^{[13]}$ In that case, the highest sensitivity was found for catechol determination, whereas the lowest one was for resorcinol. In contrast, our biosensor seems to be more sensitive for resorcinol than for hydroquinone. This finding could be explained by the influence of the optical indicator reaction used in our case. It has been described that, in general, phenols with blocked 4-position, that is, hydroquinone, exhibit very poor or decreased reactivity with MBTH chromophore in the presence of an oxidant. ${ }^{[65]}$

\subsection{Biosensor application to natural water samples analysis}

Biosensor applicability was tested in natural water samples from diverse origin (spring and river). They were preliminary analyzed confirming the absence of catechol. Then, to evaluate the reliability of our method, recovery rates were checked in spiked water samples. Recovery studies are frequently used in biosensors validation, ${ }^{[66]}$ since they permit the calculation of recovery rates of previously spiked known analyte concentrations, when the original samples are analyte-free. ${ }^{[67]}$ The results for the new biosensor are given in Table 3 and show recovery rates in the range of $97-108 \%$, proving good accuracy. One of the water samples was co-spiked with catechol and resorcinol in order to evaluate the influence of this interferent. A recovery rate of $115 \%$ was found in this case, indicating small deviation in biosensor response, even when interferent species are present.

T A B L E 3 Results of catechol determination in spiked natural water samples

\begin{tabular}{|llll|}
\hline Water sample & $\begin{array}{l}\text { Added } \\
(\boldsymbol{\mu M})\end{array}$ & $\begin{array}{l}\text { Found } \\
(\boldsymbol{\mu M})\end{array}$ & $\begin{array}{l}\text { Recovery } \\
(\%)\end{array}$ \\
\hline $\begin{array}{c}\text { Este river (Braga) } \\
\text { Spring water }\end{array}$ & 30 & 29.3 & 98 \\
$\quad 30$ & 32.4 & 108 \\
$\begin{array}{c}\text { (Moure, Braga) } \\
\text { Ave river (Taipas, } \\
\text { Guimarães) }\end{array}$ & 30 & 29.2 & 97 \\
$\begin{array}{c}\text { Ave river (Taipas, } \\
\text { Guimarães) }\end{array}$ & $\begin{array}{c}15(\mathrm{CC}) \\
+15(\mathrm{RS})\end{array}$ & 17.2 & 115 \\
\hline
\end{tabular}

Abbreviations: CC, catechol; RS, resorcinol. 


\section{4 | CONCLUSIONS}

This article presents a novel laccase-based optical biosensor for catechol determination in water samples. It represents a disposable biosensing film comprising the following components: (a) physically immobilized laccase on highly porous anionic PA6 microparticles as enzyme immobilization support; (b) a semipermeable commercial poly(ether amide) matrix that contains the optical indicator and permits the analyte diffusion while preventing enzyme leakage. Laccase immobilization is carried out by simple adsorption that avoids complicated and/or controversial protocols involving covalent binding or enzyme crosslinking. The porous anionic PA6 microparticles prepared by us and used for the first time in biosensor preparation reach excellent IYs, which is beneficial for biosensor performance. It increases the enzyme content in the biodevice, thereby improving the sensitivity toward catechol.

The biosensor response fits a linear calibration function that works in a concentration range of environmental interest between 11 and $118 \mu \mathrm{M}(1.2-13 \mathrm{mg} / \mathrm{L})$, performing better as compared to the known previously developed similar biosensors. The practical application of the new biosensor was proved by the analysis of spiked natural waters showing good accuracy.

\section{ACKNOWLEDGMENTS}

All authors gratefully acknowledge the financial support of the project TSSiPRO NORTE-01-0145-FEDER-000015, supported by the regional operation program NORTE2020, under the Portugal 2020 Partnership Agreement, through the European Regional Development Fund, as well as the support by National Funds through Fundação para a Ciência e Tecnologia (FCT), project UID/CTM/50025/2019. Special thank is due to the ALBA synchrotron governance for financing our WAXS/SAXS experiments at NCDSWEET beamline in the framework of the approved proposal ID 2018/022726. N. Dencheva is also grateful for the financial support of FCT in the frames of the strategic project UID/CTM/50025/2013 and the personal programcontract CTTI-51/18-IPC. The authors gratefully acknowledge the support of Dr. Amélie Noel (Arkema, France) for providing a free sample of Pebax ${ }^{\circledR}$ MH 1657.

\section{ORCID}

Clara Cano-Raya (1D https://orcid.org/0000-0001-61873524

Nadya V. Dencheva (1) https://orcid.org/0000-0003-1698$553 \mathrm{X}$

Joana F. Braz (1) https://orcid.org/0000-0002-6342-1967 Marc Malfois (D) https://orcid.org/0000-0001-5231-1896 Zlatan Z. Denchev (1) https://orcid.org/0000-0002-90579380

\section{REFERENCES}

[1] F. Cermola, M. Dellagreca, M. R. Iesce, S. Montella, A. Pollio, F. Temussi, Chemosphere 2004, 55, 1035. https://doi.org/10. 1016/j.chemosphere.2003.12.016.

[2] N. Schweigert, A. J. B. Zehnder, R. I. L. Eggen, Environ Microbiol. 2001, 3(2), 81. https://doi.org/10.1046/j.1462-2920. 2001.00176.x.

[3] International Agency for Research on Cancer (IARC), IARC Monographs on the Evaluation of Carcinogenic Risks to Humans, Volume 71, International Agency for Research on Cancer, 1999, p. 433.

[4] A. A. Aghapour, G. Moussavi, K. Yaghmaeian, J Environ Heal Sci Eng. 2013, 11(3), 1. https://doi.org/10.1186/2052336X-11-3.

[5] G. Lofrano, L. Rizzo, M. Grassi, V. Belgiorno, Desalination. 2009, 249(2), 878. https://doi.org/10.1016/j.desal.2009.02.068.

[6] Kanamori T, Isokawa $\mathrm{M}$, Funatsu $\mathrm{T}$, Tsunoda $\mathrm{M}$. J Chromatogr B Analyt Technol Biomed Life Sci. 2015;985: 142-148. doi:https://doi.org/10.1016/j.jchromb.2015.01.038

[7] K. Saegusa, E. Suzuki, T. Anjo, Y. Matsuki, T. Nambara, Biomed Chromatogr. 1993, 7(3), 172. https://doi.org/10.1002/ bmc. 1130070315.

[8] V. Gautam, K. P. Singh, V. L. Yadav, ACS Sustain Chem Eng. 2018, 6(2), 2256. https://doi.org/10.1021/acssuschemeng.7b03705.

[9] A. Afkhami, H. A. Khatami, J Anal Chem. 2001, 56(5), 429. https://doi.org/10.1023/A:1016670818466.

[10] Q. Ye, F. Yan, D. Kong, J. Zhang, X. Zhou, J. Xu, L. Chen, Sensors Actuators B Chem. 2017, 250, 712. https://doi.org/10.1016/ j.snb.2017.03.081.

[11] Y. Zhou, L. Tang, G. Zeng, J. Chen, Y. Cai, Y. Zhang, G. Yang, Y. Liu, C. Zhang, W. Tang, Biosens Bioelectron. 2014, 61, 519. https://doi.org/10.1016/j.bios.2014.05.063.

[12] M. N. Karim, J. E. Lee, H. J. Lee, Biosens Bioelectron. 2014, 61, 147. https://doi.org/10.1016/j.bios.2014.05.011.

[13] P. Ibarra-Escutia, J. J. Gómez, C. Calas-Blanchard, J. L. Marty, M. T. Ramírez-Silva, Talanta. 2010, 81(4), 1636. https://doi. org/10.1016/j.talanta.2010.03.017.

[14] S. Leboukh, H. Gouzi, T. Coradin, H. Yahia, J SolGel Sci Technol 2018, 86, 675. https://doi.org/10.1007/s10971-018-4696-9.

[15] J. Yuan, N. Gaponik, A. Eychmüller, ECS Trans. 2012, 50 (12), 255.

[16] M. Gamella, S. Campuzano, A. J. Reviejo, J. M. Pingarrón, J Agric Food Chem. 2006, 54(21), 7960. https://doi.org/10.1021/jf061451r.

[17] H.-F. Cui, W.-W. Wu, M.-M. Li, X. Song, Y. Lv, T.-T. Zhang, Biosens Bioelectron. 2018, 99, 223. https://doi.org/10.1016/j. bios.2017.07.068.

[18] M. M. Rodríguez-Delgado, G. S. Alemán-Nava, J. M. Rodríguez-Delgado, G. Dieck-Assad, S. O. MartínezChapa, D. Barceló, R. Parra, Trends Anal Chem 2015, 74, 21. https://doi.org/10.1016/j.trac.2015.05.008.

[19] M. Fernández-Fernández, M. Á. Sanromán, D. Moldes, Biotechnol Adv. 2013, 31, 1808. https://doi.org/10.1016/j.biotechadv. 2012.02.013.

[20] C. Silva, C. J. Silva, A. Zille, G. M. Guebitz, A. Cavaco-Paulo, Enzyme Microb Technol. 2007, 41, 867. https://doi.org/10.1016/ j.enzmictec.2007.07.010.

[21] J. Huang, H. Xiao, B. Li, J. Wang, D. Jiang, Biotechnol Appl Biochem. 2006, 44(2), 93. https://doi.org/10.1042/BA20050213.

[22] S. Z. Mazlan, S. A. Hanifah, Int J Polym Sci 2017, 2017, 1. 
[23] N. Durán, M. A. Rosa, A. D'Annibale, L. Gianfreda, Enzyme Microb Technol. 2002, 31(7), 907. https://doi.org/10.1016/ S0141-0229(02)00214-4.

[24] J. J. Roy, T. E. Abraham, K. S. Abhijith, P. V. S. Kumar, M. S. Thakur, Biosens Bioelectron 2005, 21(1), 206. https://doi. org/10.1016/j.bios.2004.08.024.

[25] J. Bryjak, P. Kruczkiewicz, A. Rekuć, W. Peczyńska-Czoch, Biochem Eng J. 2007, 35(3), 325. https://doi.org/10.1016/j.bej. 2007.01.031.

[26] D. Rochefort, L. Kouisni, K. Gendron, J Electroanal Chem. 2008, 617(1), 53. https://doi.org/10.1016/j.jelechem.2008.01.027.

[27] J. Sanz, S. de Marcos, J. Galbán, Anal Bioanal Chem 2012, 404 (2), 351. https://doi.org/10.1007/s00216-012-6061-0.

[28] V. C. Özalp, U. S. Zeydanlı, A. Lunding, M. Kavruk, M. T. Öz, F. Eyidoğan, L. F. Olsen, H. A. Öktem, Analyst. 2013, 138(15), 4255. https://doi.org/10.1039/C3AN00733B.

[29] I. Gill, Chem Mater. 2001, 13(10), 3404. https://doi.org/10. 1021/cm0102483.

[30] R. A. Simkus, V. Laurinavicius, L. Boguslavsky, T. Skotheim, S. W. Tanenbaum, J. P. Nakas, D. J. Slomczynski, Anal Lett. 1996, 29(11), 1907. https://doi.org/10.1080/00032719608000797.

[31] D. Brady, J. Jordaan, Biotechnol Lett. 2009, 31(11), 1639. https://doi.org/10.1007/s10529-009-0076-4.

[32] S. Chawla, R. Rawal, D. Kumar, C. S. Pundir, Anal Biochem. 2012, 430(1), 16. https://doi.org/10.1016/j.ab.2012.07.025.

[33] S. C. Fernandes, I. R. W. Z. de Oliveira, O. Fatibello-Filho, A. Spinelli, I. C. Vieira, Sensors Actuators B Chem. 2008, 133 (1), 202. https://doi.org/10.1016/j.snb.2008.02.023.

[34] S. K. Moccelini, A. C. Franzoi, I. C. Vieira, J. Dupont, C. W. Scheeren, Biosens Bioelectron. 2011, 26(8), 3549. https:// doi.org/10.1016/j.bios.2011.01.043.

[35] S. Singh, S. K. Mishra, B. D. Gupta, Sensors Actuators B Chem. 2013, 186, 388. https://doi.org/10.1016/j.snb.2013.06.034.

[36] J. Huang, H. Fang, C. Liu, E. Gu, D. Jiang, Anal Lett. 2008, 41 (8), 1430. https://doi.org/10.1080/00032710802119525.

[37] J. Abdullah, M. Ahmad, L. Y. Heng, N. Karuppiah, H. Sidek, Talanta. 2006, 70(3), 527. https://doi.org/10.1016/j.talanta.2005.12.061.

[38] D. Fiorentino, A. Gallone, D. Fiocco, G. Palazzo, A. Mallardi, Biosens Bioelectron. 2010, 25(9), 2033. https://doi.org/10.1016/j. bios.2010.01.033.

[39] G. B. da Silva, J. R. de Mendonça Filho, O. W. de Souza, J. C. Caldas Santos, Anal Methods 2018, 10(19), 2197. 10.1039/C8AY00464A.

[40] O. Senyurt, F. Eyidogan, R. Yılmaz, M. T. Öz, V. C. Özalp, Y. Arıca, H. A. Öktem, Biotechnol Appl Biochem. 2015, 62, 132. https://doi.org/10.1002/bab.1246.

[41] J. Abdullah, M. Ahmad, L. Y. Heng, N. Karuppiah, H. Sidek, Sensors. 2007, 7(10), 2238. https://doi.org/10.3390/s7102238.

[42] J. Gasparic, D. Svobodová, M. Pospisilová, Microchim Acta. 1977, 67(3-4), 241.

[43] N. Dencheva, Z. Denchev, S. Lanceros-Méndez, Macromol Mater Eng. 2016, 301, 119. https://doi.org/10.1002/mame.201500194.

[44] J. B. González, N. González, C. Colldelram, L. Ribó, A. Fontserè, G. Jover-Manas, J. Villanueva, M. Llonch, G. Peña, A. Gevorgyan, Y. Nikitin, J. C. Martínez, C. KammaLorger, E. Solano, I. Sics, S. Ferrer, M. Malfois. NCD-sweet beamline upgrade. In: Proceedings of the 10th mechanical engineering Design of Synchrotron Radiation Equipment and Instrumentation (MEDSI2018), 2018, 374.

[45] G. Ashiotis, A. Deschildre, Z. Nawaz, J. P. Wright, D. Karkoulis, F. E. Picca, J. Kieffer, J Appl Crystallogr. 2015, 48 (2), 510. https://doi.org/10.1107/S1600576715004306.
[46] M. Marysková, I. Ardao, C. A. García-González, L. Martinová, J. Rotková, A. Sevcu, Enzyme Microb Technol. 2016, 89, 31. https://doi.org/10.1016/j.enzmictec.2016.03.001.

[47] C. Brêda, N. Dencheva, S. Lanceros-Méndez, Z. Denchev, J Mater Sci. 2016, 51(23), 10534. https://doi.org/10.1007/s10853-016-0274-0.

[48] N. Dencheva, A. Stribeck, Z. Denchev, Eur Polym J. 2016, 81, 447. https://doi.org/10.1016/j.eurpolymj.2016.02.004.

[49] Z. Bartczak, A. Galeski, A. S. Argon, R. E. Cohen, Polymer (Guildf). 1996, 37(11), 2113. https://doi.org/10.1016/0032-3861(96)85856-3.

[50] L. E. Alexander, X-Ray Diffraction Methods in Polymer Science, Wiley- Interscience, New York 1969.

[51] N. Dencheva, T. Nunes, M. J. Oliveira, Z. Denchev, Polymer (Guildf) 2005, 46(3), 887. https://doi.org/10.1016/j.polymer. 2004.11.105.

[52] M. A. Da Silva, M. H. Gil, J. S. Redinha, A. M. O. Brett, J. L. C. Pereira, J Polym Sci Part A Polym Chem. 1991, 29(2), 275. https://doi.org/10.1002/pola.1991.080290216.

[53] S. K. S. Patel, M. Z. Anwar, A. Kumar, S. V. Otari, R. T. Pagolu, S. Y. Kim, I. W. Kim, J. K. Lee, Biochem Eng J 2018, 132, 1. https://doi.org/10.1016/j.bej.2017.12.013.

[54] H. Oktem, O. Senyurt, F. Eyidogan, C. Bayrac, R. Yilmaz, J Food Agric Environ. 2012, 10(2), 1030.

[55] J. N. Rodríguez-López, J. Escribano, F. García-Cánovas, Anal Biochem. 1994, 216, 205.

[56] I. Gul, A. Sami, S. M. S. Naqvi, M. S. Ahmad, Nucleus 2017, 54 (2), 105.

[57] J. S. Louie, I. Pinnau, I. Ciobanu, K. P. Ishida, A. Ng, M. Reinhard, J Memb Sci. 2006, 280(1), 762. https://doi.org/10. 1016/j.memsci.2006.02.041.

[58] P. Bernardo, J. Carolus, F. Bazzarelli, F. Tasselli, A. Fuoco, K. Friess, P. Izák, V. Jarmarová, M. Kačírková, G. Clarizia, Sep Purif Technol. 2012, 97, 73. https://doi.org/10.1016/j.seppur. 2012.02.041.

[59] Y. Liu, S. Yu, H. Wu, Y. Li, S. Wang, Z. Tian, J Memb Sci. 2014, 469, 198.

[60] F. Dorosti, A. Alizadehdakhel, Chem Eng Res Des. 2018, 136, 119. https://doi.org/10.1016/j.cherd.2018.01.029.

[61] G. M. Nisola, J. S. Park, A. B. Beltran, W. Chung, RSC Adv. 2012, 2, 2439. https://doi.org/10.1039/c2ra01231f.

[62] S. Pereira, M. Luis, K. Peinemann, J Memb Sci. 1995, 106, 49.

[63] D. Martinez-Pérez, M. L. Ferrer, M. C. Reyes, Anal Biochem. 2003, 322, 238. https://doi.org/10.1016/j.ab.2003.08.018.

[64] N. J. Miller, J. C. Miller, Estadística y Quimiometría Para Química Analítica, 4th ed., Prentice Hall, Madrid 2002.

[65] M. Pospisilová, M. Polasek, D. Svobodová, Mikrochim Acta. 1998, 129, 201.

[66] N. Maleki, S. Kashanian, E. Maleki, M. Nazari, Biochem Eng J. 2017, 128, 1. https://doi.org/10.1016/j.bej.2017.09.005.

[67] M. Thompson, S. L. R. Ellison, A. Fajgelj, P. Willetts, R. Wood, Pure Appl Chem. 1999, 71(2), 337.

How to cite this article: Cano-Raya $\mathrm{C}$, Dencheva NV, Braz JF, Malfois M, Denchev ZZ. Optical biosensor for catechol determination based on laccase-immobilized anionic polyamide 6 microparticles. J Appl Polym Sci. 2020;e49131. https://doi.org/10.1002/app.49131 